\title{
Unmet Need for Counseling Services by Children in New York City After the September 11th Attacks on the World Trade Center: Implications for Pediatricians
}

\author{
Gerry Fairbrother, $\mathrm{PhD}^{*} \ddagger$; Jennifer Stuber, $\mathrm{PhD}^{*}$; Sandro Galea, MD, MPH§; \\ Betty Pfefferbaum, MD, JD\|; and Alan R. Fleischman, MDII
}

\begin{abstract}
Objective. The objectives of this study were to describe the prevalence of counseling services, contrasted with the need after the terrorist attacks of September 11, 2001, the types of counseling received, and the predictors of receipt of counseling services.

Methods. A cross-sectional, random-digit-dial survey was conducted in New York City (NYC) of parents $(N=$ 434) of children who were 4 to 17 years of age 4 months after the September 11th terrorist attacks on the World Trade Center.

Results. Overall, $10 \%$ of NYC children received some type of counseling after the September 11th attacks, according to parental report. Among these, 44\% received counseling in schools, $36 \%$ received counseling from medical or professional providers, and $20 \%$ received counseling from other sources. However, only $27 \%$ of the children who had severe/very severe posttraumatic stress reactions (PTSR) after the attacks received counseling services. In a multivariate model, receipt of counseling before the September 11th attacks (odds ratio: 4.44 ) and having severe/very severe PTSR (odds ratio: 3.59) were the most important predictors of use of counseling services after the September 11th attacks. Minority status and having a parent who experienced the loss of a friend or a relative were also associated with receipt of services.

Conclusions. There was substantial disparity between apparent need (as indicated by severe/very severe PTSR) for and receipt of mental health services for children after the September 11th attacks. There is need for intensified efforts to identify, refer, and treat children in need, especially for children who are not already in a therapeutic relationship. An enhanced role for pediatricians is indicated. Pediatrics 2004;113:1367-1374; posttraumatic stress reactions, children, disaster, trauma.
\end{abstract}

ABBREVIATIONS. NYC, New York City; PTSD, posttraumatic stress disorder; PTSR, posttraumatic stress reactions; DSM-IV, Diagnostic and Statistical Manual of Mental Disorders, Fourth Edition; OR, odds ratio.

From the *Division of Health and Science Policy, New York Academy of

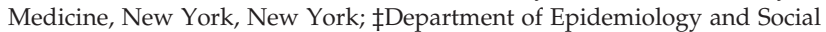
Medicine, Albert Einstein College of Medicine, New York, New York; $\S$ Center for Urban Epidemiologic Studies, New York Academy of Medicine, New York, New York; |Department of Psychiatry, University of Oklahoma College of Medicine, Oklahoma City, Oklahoma; and IICenter for Urban Bioethics, The New York Academy of Medicine, New York, New York. Received for publication Jun 24, 2003; accepted Oct 3, 2003.

Reprints requests to (G.F.) New York Academy of Medicine, 1216 Fifth Ave, New York, NY 10029-5283. E-mail: gfairbro@NYAM.org

PEDIATRICS (ISSN 0031 4005). Copyright (c) 2004 by the American Academy of Pediatrics.
1 The terrorist attacks of September 11, 2001, on New York City (NYC) were the largest humanmade intentional disaster in US history. The sheer scope of the attacks, the level of property destruction, the financial repercussions, and the continuing level of anxiety suggested that these attacks might have mental health consequences both for direct victims of the attacks and for the population at large. We have previously shown that $7.5 \%$ of adults population-wide had symptoms consistent with posttraumatic stress disorder (PTSD) and 9.7\% with depression in the first 2 months after the attacks. ${ }^{1}$ Furthermore, $\sim 18 \%$ of NYC's children had severe or very severe posttraumatic stress reactions (PTSR), as determined from information provided by their parents, ${ }^{2}$ and $27 \%$ of school children in grades 4 through 12 met criteria for 1 or more of 7 psychiatric disorders and also reported problems in their day-to-day functioning. 3

In recent years, evidence has been accumulating about the effectiveness of interventions for children's mental health disorders. ${ }^{4}$ It is important to bring this knowledge to bear in treating children after a disaster. However, children's access to mental health services depends on a variety of factors, including the availability of services, the ability of parents and other adults to recognize the child's need for services, the parent's ability to navigate the health care system and, at times, the ability to pay for services. The response to the needs of direct victims after the September 11 th attacks was immediate. With support from the federal government, state and local mental health authorities established "Project Liberty," a large-scale intervention aimed at providing services to those in need. ${ }^{5}$ Furthermore, the Board of Education mounted a major assessment of the mental health needs of children in the schools. ${ }^{3}$ Mental health workers and pediatricians volunteered their services in the schools that were hit hardest by the disaster.

Although data have been presented about overall mental health service use for adults, 6,7 we know less about the use of counseling services by children in NYC after the September 11th attacks. We previously examined receipt of counseling by children in the immediate vicinity of the World Trade Center and reported that $25 \%$ of the children had received counseling related to the disaster, with more than half of the counseling (58\%) delivered in the schools. ${ }^{8}$ Coun- 
seling, in this previous study, included both group counseling in classrooms and individual counseling. The parents' own level of posttraumatic stress was an important predictor of whether their children received counseling. Although this previous study provided important information just 1 month after the disaster, it was limited in its size (just 112 parents), in geographical reach (only included households in close proximity to the World Trade Center), and in the predictors that it could examine. Furthermore, this earlier study was not able to relate receipt of counseling to need for counseling or to the receipt of counseling before September 11th.

In this article, we report results from a subsequent survey conducted in January and February 2003, with a larger sample of parents throughout NYC. The purpose of this article is to describe the level and type of counseling for children in NYC generally, to describe the level of unmet need for counseling, to examine predictors of receipt of counseling, and to explore the policy implications of providing counseling services to children in need. Because the September 11th attacks on the World Trade Center may not be the last terrorist attack that our country will experience, it is important to understand the successes and problems encountered in responding to the September 11th attacks so that corrective action can be taken. This research is also relevant to mounting an effective response to natural and technologic disasters that have far-reaching impacts on the community. It is also important to explore the response to September 11th with an eye toward determining what role pediatricians might play in terrorism preparedness.

\section{METHODS}

\section{Data Collection and Sample}

Data were collected through telephone interviews with a random sample of 2001 adults (18 years of age or older) conducted between January 15 and February 21, 2002, 4 to 5 months after the September 11th attacks. The sampling frame included all adults in NYC with an oversampling of residents who live south of 110th Street. A random adult in the household was selected using the last birthday procedure. Adults who were the parent or primary caregiver of a child who was between the ages of 4 and 17 and lived in the household were asked to respond to an additional set of child-oriented questions. Parents with $>1$ child in that age range were asked to respond to questions about the child who had most recently celebrated a birthday. Interviews were conducted in English and Spanish using computer-assisted telephone interviewing. The overall cooperation rate for the survey was $60 \%$. Sampling weights were developed and applied to the data to correct potential selection bias related to the number of telephones and children in the household. The study was approved by the Institutional Review Board at The New York Academy of Medicine, and procedures were in place to provide study participants with immediate assistance in obtaining counseling if needed. (Need was determined through questions at the end of the survey that asked whether the respondent needed assistance and, if so, whether they needed assistance right away or the next morning. A psychiatrist was on call during the period of the survey to respond.)

\section{Instrument}

Respondents were interviewed using a structured questionnaire that was $\sim 35$ minutes in length. Parents were asked about demographic/biographic characteristics of the focal child and the family, including the child's gender, age, and race/ethnicity and whether the child had siblings. Parents were also asked about whether the child had health insurance and about household characteristics, such as the number of parents in the household, annual household income, and the borough of residence on September 11th.

Parents were asked about their own mental health status using a measure of PTSD and major depression temporally linked to the September 11th attacks. The PTSD measure for parents was a modified version of the Diagnostic Interview Schedule based on the Diagnostic and Statistical Manual of Mental Disorders, Fourth Edition (DSM-IV). ${ }^{1,9,10}$ It has a coefficient of agreement with clinician-administered structured clinical interviews of 0.71 for current PTSD and 0.77 for lifetime PTSD. ${ }^{11,12}$ A modified version of the Structured Clinical Interview for DSM-IV for a major depressive episode was used to determine the presence of depression in parents. ${ }^{1,11,13}$ They were also asked whether they knew someone who had been killed (a friend or a relative) and whether they had cried in front of the child.

Parents were asked about the child's disaster-related PTSR. Posttraumatic stress in children was ascertained using the PostTraumatic Stress Disorder Reaction Index-Child Revision, ${ }^{14}$ a 20item index that measures children's degree of reaction to trauma; scores indicate degree of disorder in 5 categories: doubtful, mild, moderate, severe, and very severe. In this survey, parents reported on the degree of reaction for their children. Items in this index cluster on 3 factors: reexperiencing/numbing, fear/anxiety, and concentration/sleep, which partially overlap with the 3 DSM-IV factors of reexperiencing, arousal, and avoidance. Internal consistency ranges from 0.69 to 0.80 for the 3 scales. $^{15}$

Receipt of counseling services before and after the September 11th attacks were ascertained. Use of counseling services after the September 11th attacks was determined by asking the parent whether the child had received any counseling related to his or her experiences from the September 11th attacks and, if so, who provided the counseling.

\section{Statistical Analyses}

We calculated the prevalence of mental health service use, overall and by types of mental health services. We also calculated the overall prevalence of mental health service use according to the covariates of interest. Two-tailed $\chi^{2}$ tests were used to identify associations between covariates and use of counseling services. Multivariate logistic regression was used to examine predictors of counseling. Covariates were included in the multivariate regression model when the bivariate $\chi^{2} P$ values were $<.1$. Analyses were weighted to compensate for potential bias as a result of the number of adults in a household and the number of telephones. Standard errors were calculated and significance was determined using SUDAAN ${ }^{16}$ software to account for the complex survey design.

\section{RESULTS}

\section{Sample Characteristics}

Among the 2001 adults surveyed, 434 reported that they were the parent of at least 1 child who was living in their household. Table 1 shows the characteristics of these children. Slightly more than half (55\%) of these children were boys. Overall, $58 \%$ were school age (4-11 years of age), and $42 \%$ were adolescents (12-17 years of age). With respect to race, $30 \%$ were non-Hispanic white, $37 \%$ were non-Hispanic black, $27 \%$ were Hispanic, and $6 \%$ were some other race/ethnicity. Most (73\%) of these children had siblings, lived in 2-parent families $(65 \%)$, and lived in households with incomes $>\$ 40000$ (54\%). Most of the children in our sample lived in Brooklyn $(39 \%)$, but $26 \%$ lived in Queens, $16 \%$ lived in the Bronx, $11 \%$ lived in Manhattan, and $8 \%$ lived in Staten Island. Age, gender, race or ethnic group, and residence distributions in the overall sample were similar to estimates obtained from the 2000 US Census for our sampling frame. ${ }^{17}$

Parents varied in their reaction to disaster; $9 \%$ had 


\begin{tabular}{|c|c|c|}
\hline & \multicolumn{2}{|c|}{ All Focal Children $(n=434)$} \\
\hline & $n$ & Weighted \% \\
\hline \multicolumn{3}{|c|}{ Child and family demographic characteristics } \\
\hline \multicolumn{3}{|c|}{ Gender } \\
\hline Male & 233 & 55 \\
\hline Female & 194 & 45 \\
\hline \multicolumn{3}{|l|}{ Age of child, $y$} \\
\hline $4-11$ & 248 & 58 \\
\hline $12-17$ & 178 & 42 \\
\hline \multicolumn{3}{|l|}{ Race of child } \\
\hline Non-Hispanic black & 146 & 37 \\
\hline Non-Hispanic white & 141 & 30 \\
\hline Hispanic & 115 & 27 \\
\hline Other & 27 & 6 \\
\hline Child has siblings & 224 & 73 \\
\hline Single-parent household & 157 & 35 \\
\hline \multicolumn{3}{|l|}{ Household income } \\
\hline$\$ 0-\$ 40000$ & 182 & 46 \\
\hline$>\$ 40000$ & 252 & 54 \\
\hline \multicolumn{3}{|l|}{ Borough where child lived on $9 / 11$} \\
\hline Bronx & 68 & 16 \\
\hline Brooklyn & 145 & 39 \\
\hline Queens & 112 & 26 \\
\hline Manhattan & 70 & 11 \\
\hline Staten Island & 32 & 8 \\
\hline Child has health insurance & 406 & 97 \\
\hline \multicolumn{3}{|c|}{ Parent's reaction to/experience with the disaster } \\
\hline Parental PTSD since $9 / 11$ & 37 & 9 \\
\hline Parental depression since $9 / 11$ & 42 & 11 \\
\hline Crying in front of child & 139 & 33 \\
\hline Relative or friend of parent killed & 62 & 14 \\
\hline \multicolumn{3}{|c|}{ Child's mental health experience before disaster } \\
\hline Received counseling before $9 / 11$ & 42 & 9 \\
\hline \multicolumn{3}{|c|}{ Child's Posttraumatic stress after disaster } \\
\hline \multicolumn{3}{|c|}{ Children's PTSR } \\
\hline Doubtful or mild & 17 & 16 \\
\hline Moderate & 277 & 66 \\
\hline Severe & 62 & 15 \\
\hline Very severe & 13 & 3 \\
\hline
\end{tabular}

* Values may not sum to the expected $N$ because of missing data.

t All results are weighted using sample weights to adjust for the number of telephone lines and children in the houshold and for the Manhatan oversample.

symptoms consistent with PTSD and $11 \%$ with depression since September 11th. One third (33\%) cried in front of their children, and $14 \%$ knew a friend or a relative who was killed during the attacks.

Most $(91 \%)$ children had never received counseling before the September 11th attacks, and although most (96\%) had health insurance, we do not know whether the insurance covered counseling. After the attacks, $18 \%$ exhibited severe or very severe PTSR.

\section{Prevalence of Mental Health Service Use Overall and for Children With Severe/Very Severe PTSR}

Citywide, $10 \%$ of the children received counseling or mental health services after the September 11th attacks, as shown in Table 2. Most (44\%) of the counseling was conducted in the schools, by teachers $(14 \%)$ or school psychologists or counselors (30\%). Another $36 \%$ was conducted by mental health professionals outside the schools, including psychiatrists, psychologists, therapists, and social workers. The remaining $20 \%$ was conducted by religious leaders and by unspecified or unknown others. Of those children who received counseling services, $47 \%$ had severe or very severe PTSR, $50 \%$ had moderate PTSR, and 3\% had mild PTSR. One third of the children who received counseling services after the September 11th attacks had received counseling before the attacks as well. For children who lived below 110th street (closer proximity to the World Trade Center), 20\% received mental health services (data not shown).

To assess use of mental services against need for services, we examined the use of mental health services by children who had more severe PTSR and who exhibited behavior problems. Only $27 \%$ of the children who had severe or very severe PTSR received counseling.

\section{Bivariate Analysis}

Unadjusted odds ratios (ORs; Table 3) show that the variables most strongly associated with the child's obtaining counseling after the September 11th attacks were having counseling at any time before the attacks (unadjusted OR: 7.09; $P<.0001$ ) and having severe or very severe PTSR (unadjusted OR: 4.99; $P<$.0001). Demographic variables associated with receipt of mental health services included living in a single-parent household and race. Children in a single-parent household had almost 3 times the odds of receiving mental health services as their counter- 


\begin{tabular}{lc}
\hline & $\begin{array}{c}\% \text { of Children } \\
\text { Receiving Services* }\end{array}$ \\
\hline \% of children who received counseling $(n=434)$ & $10 \%$ \\
For children who received counseling services $(n=40)$ & \\
$\%$ Receiving services from & $14 \%$ \\
Teacher & $30 \%$ \\
School psychologist/counselor & $36 \%$ \\
Mental health professional outside school & $20 \%$ \\
Religious leader/unspecified & \\
\% With PTSR severity levels & $47 \%$ \\
Severe/very severe PTSR & $50 \%$ \\
Moderate PTSR & $3 \%$ \\
Mild PTSR & $33 \%$ \\
For children with severe/very severe PTSR $(n=75)$ & $27 \%$ \\
$\%$ Who received counseling & \\
\hline
\end{tabular}

* All results are weighted using sample weights to adjust for the number of telephone lines and children in the household and for the Manhattan oversample.

parts in 2-parent households (unadjusted OR: 2.75; $P$ $<$.007). With respect to race, non-Hispanic black, Hispanic, and other children were more likely to receive mental health services than their non-Hispanic white counterparts (unadjusted OR: 2.96; $P<$ $.01)$.

\section{Multivariate Analysis}

In a multivariate model (Table 4), obtaining counseling for the child before the September 11th attacks (adjusted OR: 4.44, $P<.005$ ) and child's having severe/very severe PTSR (adjusted OR: 3.59; $P<$ .002) continued to be strongest predictors of receipt of counseling services after the attacks. With respect to demographic variables, non-Hispanic black, Hispanic, and other children had higher odds of receiving counseling services than their non-Hispanic white counterparts (adjusted OR: $3.59, P<.02$ ). With respect to parental reactions and experiences with the disaster, parental PTSD and crying in front of the child were no longer significantly related to the child's receipt of counseling services in the multivariate model, but the parent's having a relative or a friend killed continued to be significantly associated with child's receipt of counseling services (adjusted OR: 3.02; $P<.02$ ).

\section{DISCUSSION}

This study found that overall, $10 \%$ of children in NYC received counseling after the September 11th attacks but that only $27 \%$ of children with severe or very severe PTSR received these services. Although children with severe or very severe PTSR were more likely to receive mental health services than children with less severe reactions, these data suggest that there may be extensive unmet need among the children who were most affected by the September 11th attacks at the time of this study, 4 months after these attacks. It will be important to monitor the level of unmet needs as more counseling services are put into place in the school systems, as part of NYC's Project Liberty, ${ }^{5,18}$ and elsewhere.

Our findings of disparity between need, as indicated by severe or very severe PTSR, and receipt of mental health services are consistent with a study of
NYC school children, which showed that only $34 \%$ of those with probable PTSD and impaired functioning in the months after the September 11th attacks received counseling, either inside or outside the schools. ${ }^{3}$ This high level of unmet need for mental health services after the September 11th attacks should be viewed in the context of high levels of unmet need for children's mental health care generally. ${ }^{19,20}$

We found that almost half (44\%) of the counseling after the September 11th attacks was provided through the schools, with a little more than third (36\%) provided by mental health professionals outside the schools. The $44 \%$ counseling in schools includes that given by teachers $(14 \%)$ as well as school psychologists or counselors (30\%). Although teachers are typically not trained counselors, they are seen as natural support figures to whom children and parents turn in a crisis. Other studies show schools as major providers of mental health services for children in ordinary times ${ }^{20}$ and of emergency and short-term mental health services after a disaster. ${ }^{21,22}$ Location of mental health services in schools makes sense as a public health approach, given that services are convenient to the children and service use and dropout can be monitored. ${ }^{18}$

The 2 most important predictors of receipt of counseling services in this study were having severe/very severe PTSR and having had previous counseling. That severity of PTSR should predict receipt of counseling services is appropriate and not surprising. The importance of previous counseling as a predictor could be the result of either or both of 2 scenarios. First, previous receipt of counseling services could be an indication of previous emotional or behavioral problems for these children, which in turn could be an indication of stress, disruption, or even trauma in these children's lives. All of these factors have been shown to be related to intensified stress reactions of children in a new trauma. ${ }^{23}$ An additional scenario is that children with previous counseling had already established contacts with the mental health system, so when a new need arose for them after September 11th, they could engage these contacts readily. Having had previous services may also indicate recep- 
TABLE 3. Bivariate Associations Between Receiving Mental Health Services and Covariates of Interest Unadjusted ORs and 95\% Confidence Intervals $(n=434)$

\begin{tabular}{|c|c|c|c|}
\hline & $\begin{array}{c}\text { OR } \\
\text { (Unadjusted) }\end{array}$ & $\begin{array}{l}\text { Confidence } \\
\text { Intervals }\end{array}$ & $P$ Value \\
\hline \multicolumn{4}{|c|}{ Child and family demographic characteristics } \\
\hline \multicolumn{4}{|c|}{ Gender } \\
\hline Male & - & - & - \\
\hline Female & 1.24 & $0.59-2.58$ & .57 \\
\hline \multicolumn{4}{|l|}{ Age of child, $y$} \\
\hline $4-11$ & - & - & - \\
\hline $12-17$ & 1.37 & $0.30-6.23$ & .68 \\
\hline \multicolumn{4}{|l|}{ Race of child } \\
\hline Black, Hispanic, and other & 2.96 & $1.25-7.01$ & .01 \\
\hline Non-Hispanic white & - & - & - \\
\hline \multicolumn{4}{|l|}{ Child has siblings } \\
\hline Yes & 1.37 & $0.69-2.71$ & .37 \\
\hline No & - & - & - \\
\hline \multicolumn{4}{|l|}{ Single-parent household } \\
\hline Yes & 2.75 & $1.32-5.75$ & .007 \\
\hline No & - & - & - \\
\hline \multicolumn{4}{|l|}{ Household income } \\
\hline$\$ 0-\$ 40000$ & - & - & - \\
\hline$>\$ 40000$ & 0.91 & $0.29-2.87$ & .88 \\
\hline \multicolumn{4}{|c|}{ Borough where child lived on $9 / 11$} \\
\hline Bronx & 0.24 & $0.05-1.15$ & .07 \\
\hline Brooklyn & 0.38 & $0.13-1.16$ & .09 \\
\hline Queens & 0.54 & $0.18-1.62$ & .27 \\
\hline Staten Island & 0.24 & $0.04-1.40$ & .11 \\
\hline Manhattan & - & - & - \\
\hline \multicolumn{4}{|l|}{ Child has health insurance } \\
\hline Yes & 1.32 & $0.17-10.42$ & .79 \\
\hline No & - & - & - \\
\hline \multicolumn{4}{|c|}{ Parent's reaction to/experience with the disaster } \\
\hline \multicolumn{4}{|l|}{ Parental PTSD since 9/11 } \\
\hline Yes & 2.78 & $0.90-8.57$ & .07 \\
\hline No & - & - & - \\
\hline \multicolumn{4}{|l|}{ Parental depression since $9 / 11$} \\
\hline Yes & 1.27 & $0.44-3.67$ & .66 \\
\hline No & - & - & - \\
\hline \multicolumn{4}{|l|}{ Crying in front of child } \\
\hline Yes & 2.01 & $0.95-8.57$ & .07 \\
\hline No & - & - & - \\
\hline \multicolumn{4}{|l|}{ Relative or friend killed } \\
\hline Yes & 2.34 & $0.98-5.61$ & .06 \\
\hline No & - & - & - \\
\hline \multicolumn{4}{|c|}{ Child's mental health experiences before disaster } \\
\hline \multicolumn{4}{|l|}{ Received counseling before 9/11 } \\
\hline Yes & 7.09 & 2.96-16.99 & .0001 \\
\hline No & - & - & - \\
\hline \multicolumn{4}{|c|}{ Child's posttraumatic stress after disaster } \\
\hline \multicolumn{4}{|c|}{ Children's PTSR severe or very severe } \\
\hline Yes & 4.99 & $2.31-10.82$ & .0001 \\
\hline No & - & - & - \\
\hline
\end{tabular}

tiveness to counseling. Previous use of services is a strong predictor of current use of services ${ }^{24}$ for a variety of health care services. The relationships that we see for counseling could be part of these larger patterns of access and use.

Despite the high predictive value of these variables, it is important to note that counseling services were given to many children with more moderate symptoms and with no immediate history of receiving counseling services. Specifically, approximately half of the children who received counseling had severe or very severe PTSR, whereas the remaining half had only moderate symptoms.

Parental exposure and reactions to the September 11th attacks were determinants of receipt of counseling for their children. In bivariate analyses, parents with PTSD, parents who had experienced the loss of a friend or a relative, and parents who cried in front of their children were more likely to have children in counseling than parents who did not have these experiences or reactions, although the significance fell slightly below traditional levels. In the bivariate analysis, it is not possible to determine which form of exposure is most significant. Although in a multivariate analysis that included all 3 variables only parent's having a friend or a relative killed persisted in having a significant association with children's receipt of counseling, it is still clear that parents' reactions and/or exposure to a disaster is related to their children's receipt of counseling. This finding in the present study 4 months after the disaster is consistent with earlier findings 1 month after the disaster. ${ }^{8}$ There are several explanations for the relationship between parental functioning and children's receipt 
TABLE 4. Multivariate Model Showing Relationships Between Receipt of Mental Health Services and Covariates of Interest Adjusted ORs and 95\% Confidence Intervals $(n=434)$

\begin{tabular}{|c|c|c|c|}
\hline & $\begin{array}{c}\text { OR } \\
\text { (Adjusted) }\end{array}$ & $\begin{array}{l}\text { Confidence } \\
\text { Intervals }\end{array}$ & $P$ Value \\
\hline \multicolumn{4}{|c|}{ Child and family demographic chracteristics } \\
\hline \multicolumn{4}{|l|}{ Race of child } \\
\hline Black, Hispanic, and other & 3.59 & $1.23-10.51$ & .02 \\
\hline Non-Hispanic white & - & - & - \\
\hline \multicolumn{4}{|l|}{ Single-parent household } \\
\hline Yes & 1.87 & $0.82-4.24$ & .13 \\
\hline No & - & - & - \\
\hline \multicolumn{4}{|c|}{ Borough where child lived on $9-11$} \\
\hline Bronx & 0.27 & $0.07-1.13$ & .07 \\
\hline Brooklyn & 0.55 & $0.17-1.73$ & .31 \\
\hline Queens & 1.23 & $0.37-4.04$ & .74 \\
\hline Staten Island & 0.76 & $0.12-4.94$ & .77 \\
\hline Manhattan & - & - & - \\
\hline \multicolumn{4}{|c|}{ Parent's reaction to/experience with the disaster } \\
\hline \multicolumn{4}{|l|}{ Parental PTSD since 9-11 } \\
\hline Yes & 0.79 & $0.25-2.51$ & .69 \\
\hline No & - & - & - \\
\hline \multicolumn{4}{|l|}{ Crying in front of child } \\
\hline Yes & 1.60 & $0.71-3.59$ & .26 \\
\hline No & - & - & - \\
\hline \multicolumn{4}{|l|}{ Relative or friend killed } \\
\hline Yes & 3.02 & $1.16-77.90$ & .02 \\
\hline No & - & - & - \\
\hline \multicolumn{4}{|c|}{ Child's mental health experiences before disaster } \\
\hline \multicolumn{4}{|c|}{ Received counseling before September 11} \\
\hline Yes & 4.44 & $1.59-12.41$ & .005 \\
\hline No & - & - & - \\
\hline \multicolumn{4}{|c|}{ Child's posttraumatic stress after disaster } \\
\hline \multicolumn{4}{|c|}{ Child's PTSR is severe or very severe } \\
\hline Yes & 3.59 & $1.63-7.92$ & .002 \\
\hline No & - & - & - \\
\hline
\end{tabular}

of counseling services. First, the intensity of parental reactions and poor parental functioning may be associated with children's developing psychiatric symptoms after a disaster. ${ }^{25-28}$ These symptoms in the child may, then, lead to the child's being identified as needing counseling services. A second explanation is that parents' own symptoms may affect their decisions about seeking care for their children. This is consistent with other research outside the disaster setting that has documented the importance of parental help-seeking behavior in receipt of mental health services for children who need them. ${ }^{29,30}$

Related findings from our study suggest that family vulnerability, such as single-parent households (in the bivariate analysis), and minority status (in both bivariate and multivariate analyses) were associated with receipt of services. However, previous research has also linked economic disadvantage, low income, or adversities with unmet need for mental health care as well as health care in general. ${ }^{29,31}$ These findings are not necessarily inconsistent, but they do point to the complexity of the process by which children receive services.

This study has a number of policy implications. First, with respect to the role in screening, the low level of counseling services for children with severe or very severe PTSR indicates the importance of outreach after traumatic events to screen and refer children who need mental health services. School-based screening for disaster-related mental health care is logical because large numbers of children can be reached in an environment that encourages nor- malcy and minimizes stigma. ${ }^{23}$ Teachers (and parents) often respond to externalizing symptoms and, less frequently, to anxiety and depression. Thus, screening that allows the child to self-report experiences and reactions is essential. Although teachers (and parents) could and perhaps should be taught to recognize internalizing symptoms, mental health screening by teachers would not be appropriate because it would require them to address issues for which they have not been adequately trained, raises confidentiality issues, creates confusion with their role as educator, and adds additional burden.

Pediatricians, however, can play an important role in this regard. In ordinary times, between $60 \%$ and $70 \%$ of school-aged children visit a physician annually, ${ }^{32}$ and children with behavior problems do so more frequently. ${ }^{33}$ Thus, children with PTSR may be especially likely to visit the physician because of increased likelihood of somatic manifestations. ${ }^{34}$ This suggests that there may be a need for a stronger role for pediatricians, both in screening to identify children who need services and possibly in the provision of services for less severe cases. It may be important for pediatricians to screen all children who visit their practice after a disaster for potential mental health needs. If there are indications that our country will be subjected to future terrorist attacks, then it is necessary to begin to determine how to make it possible for pediatricians to assume an expanded role.

Pediatricians may need additional training to fulfill this role. Past studies have shown that pediatri- 
cians have difficulty diagnosing psychiatric disorders 35,36 ; thus, specific education and training are essential. Pediatricians would also need to know where to refer severe cases, and this indicates the need for greater knowledge of the mental health system and help in gaining that knowledge.

Mental health professionals should have a clear role in delivery of services to the children with psychopathology after disaster. Experts have advocated for enhanced efforts in all service sectors that see children: the welfare and juvenile justice systems, in foster care, and, especially in the educational system, ${ }^{18,37}$ because schools already are key providers of mental health services for children. ${ }^{20}$ However, there is likely to be a role for pediatricians in treatment of the less severe cases. Much of this treatment involves psychoeducation that could well be provided by pediatricians. Studies have documented substantial levels of unmet needs among children for mental health services in ordinary times, ${ }^{31}$ and the dearth of mental health services for the general population would be more acute after a disaster. That more than half of the children who received counseling services had moderate or mild PTSR indicates the need for support services for children in the population at large after a disaster as well as the need to direct the most severe cases to mental health professionals. Of course, if pediatricians were to assume a role in screening all children and treating the less severe, then additional training and reimbursement for the added services would need to be available. In at least 1 state, pediatricians are advocating for this larger role in provision of mental and behavioral health services to children, with appropriate financial support. $^{38}$

This study had several limitations. First, we could not describe well the frequency of mental health service use or describe features such as whether the counseling was in a group or individual. Counseling provided by a teacher in a classroom is very different from services provided by a mental health professional over an extended time period. Second, we relied on parents' report of their children's receipt of counseling, which might be less accurate than the children's own report, particularly for older adolescents. Third, we did not measure functional impairment. We used PTSR as an indicator of need, but most rigorous definitions of need would use both psychopathology and associated functional impairment (which is often associated with service use). ${ }^{31} \mathrm{~A}$ final limitation of this study was that our sample was too small to conduct important subgroup analyses. For example, it was too small to ascertain whether the children who needed but did not receive mental health services were systematically different from those who needed but received services.

Despite its limitations, this study provides insight into the need for and utilization of counseling services after a disaster and highlights the need for additional efforts to identify children who may require services. It also indicated the particular importance of outreach for children who are not currently in a therapeutic relationship. Finally, this study suggests a stronger role for pediatricians after a disaster in screening and referral for the most severe cases and for treating the less severe. Educational initiatives and adequate funding are needed for pediatricians to fill this role.

\section{ACKNOWLEDGMENTS}

This research was supported by grants form the National Institute of Mental Health (grant MH66385), the William T. Grant Foundation, the United Way of New York City and the New York Community Trust, the National Institute on Drug Abuse of the National Institutes of Health (grant R01 DA14219-01S1), the Commonwealth Fund (grant 20020230), and the National Institute of Mental Health (grant RO1 MH 66081-01).

\section{REFERENCES}

1. Galea S, Ahern J, Resnick H, et al. Psychological sequelae of the September 11th attacks in New York City. N Engl J Med. 2002;346:982-987

2. Fairbrother G, Stuber J, Galea S, Fleischman AR, Pfefferbaum B. PostTraumatic Stress Reaction in New York City Children After September 11th Terrorist Attacks. Final Report to William T. Grant Foundation. New York, NY: New York Academy of Medicine; 2003

3. Hoven CW, Duarte CS, Mandell CP, et al. Effects of the World Trade Center Attack on NYC Public School Students-Initial Report to the New York City Board of Education. New York, NY: Columbia University Mailman School of Public Health-New York State Psychiatric Institute and Applied Research and Consulting; 2002

4. Burns BJ, Hoagwood K, Mrazek PJ. Effective treatment for mental disorders in children and adolescents. Clin Child Fam Psychol Rev. 1999; 2:199-254

5. Felton C. Project Liberty: a public health response to New Yorkers' mental health needs arising from the World Trade Center terrorist attacks. J Urban Health. 2002;79:429-433

6. Herman D, Felton C, Susser E. Mental health needs in New York State following the September 11th attacks. J Urban Health. 2002;79:322-331

7. Boscarino JA, Galea S, Ahern J, Resnick H, Vlahov D. Utilization of mental health services following the September 11th terrorist attacks in Manhattan, New York City. Int J Emerg Ment Health. 2002;4:143-155

8. Stuber J, Fairbrother G, Galea S, Pfefferbaum B, Wilson-Genderson M, Vlahov D. Determinants of counseling for children in Manhattan after the September 11th attacks. Psychiatr Serv. 2002;53:815-822

9. Robins LN, Marcus L, Reich W, Cunningham R, Gallagher T. NIMH Diagnostic Interview Schedule, Version IV. St Louis, MO: Department of Psychiatry, Washington School of Medicine; 1996

10. American Psychiatric Association. Diagnostic and Statistical Manual of Mental Disorders. 4th ed. Washington, DC: American Psychiatric Association; 1994

11. Kilpatrick DG, Resnick HS, Freedy JR, et al. The posttraumatic stress disorder field trial: evaluation of the PTSD construct-criteria A through E. In: Widiger T, Frances A, Pincus H, et al., eds. DSM-IV Sourcebook. Vol 4. Washington, DC: American Psychiatric Association Press; 1998:803-844

12. Resnick HS, Kilpatrick DG, Dansky BS, Saunders BE, Best CL. Prevalence of civilian trauma and posttraumatic stress disorder in a representative national survey of women. J Consult Clin Psychol. 1993;61: 984-991

13. First MB, Spitzer RL, Williams JBW, Gibbon M. Structured Clinical Interview for DSM-IV Axis I Disorders (SCID-I): User's Guide and Interview. Washington, DC: American Psychiatric Association Press; 1997

14. Pynoos RS, Frederick C, Nader K, et al. Life threat and posttraumatic stress in school-age children. Arch Gen Psychiatry. 1987;44:1057-1063

15. Ohan JL, Myers K, Collett B. Ten-year review of rating scales. IV scales assessing trauma and its effects. J Am Acad Child Adolesc Psychiatry. 2002;41:1401-1422

16. Shah B, Barnewell B, Bieler G. SUDAAN User's Manual. Release 7.5. Research Triangle Park, NC: Research Triangle Institute; 1997

17. Bureau of the Census. Census Summary Tape, File 3A (STF3A). Washington, DC: Department of Commerce; 2000 (data file)

18. Citizens' Committee for Children. Paving the Way: New Directions for Children's Mental Health Treatment Services. New York, NY: Citizens' Committee for Children; 2002

19. Leaf PJ, Alegria M, Cohen P, et al. Mental health service use in the community and schools: results from the four-community MECA study. J Am Acad Child Adolesc Psychiatry. 1996;35:889-897

20. Burns BJ, Costello EJ, Angold A, et al. Children's mental health services use across service sectors. Health Aff. 1995;14:147-159 
21. Flynn B, Nelson M. Understanding the needs of children following large-scale disasters and the role of government. Child Adolesc Psychiatr Clin N Am. 1999;1:211-227

22. Pynoos R, Goenijian A, Steinberg A. A public mental health approach to the post-disaster treatment of children and adolescents. Child Adolesc Psychiatr Clin N Am. 1998;7:195-210

23. Pfefferbaum B. Treating children exposed to disasters. Arch Pediatr Adolesc Med. 2002;156:208 (editorial)

24. Janicke DM, Finney JW, Riley AW. Children's health care use a prospective investigation of factors related to care seeking. Med Care.2001; 39:990-1001

25. Green B, Korol M, Grace M, et al. Children and disaster: age gender, and parental effects on PTSD symptoms. J Am Acad Child Adolesc Psychiatry. 1991;30:945-95

26. Laor N, Wolmer L, Mayes LC, Gershon A, Weizan R, Cohen DJ. Israeli preschool children under scuds: a 30-month follow-up. J Am Acad Child Adolesc Psychiatry. 1997;36:349-356

27. McFarlane AC. The relationship between patterns of family interactions and psychiatric disorder in children. Aust N Z J Psychiatry. 1987;21: 383-390

28. McFarlane AC. Family functioning and overprotection following a natural disaster: the longitudinal effects of post-traumatic morbidity. Aust N Z J Psychiatry. 1987;21:210-218

29. Pavuluri MN, Luk S, McGee R. Help-seeking for behavior problems by parents for behavior problems by parents of preschool children: a community study. J Am Acad Child Adolesc Psychiatry. 1996;35:215-222

30. Feehan M, Stanton W, McGee R, Silva PA. Parental help-seeking for behavioral and emotional problems in childhood and adolescence. Community Health Stud. 1990;14:303-309

31. Flisher AJ, Kramer RA, Grosser RC, et al. Correlates of unmet need for mental health services by children and adolescents. Psychol Med. 1997; 27:1145-1154

32. Elixhauser A, Machlin SR, Zodet MW, et al. Health care for children and youth in the United States: 2001 annual report on access, utilization, quality, and expenditures. Ambul Pediatr. 2002;2:419-437

33. Zuckerman B, Moore KA, Glei D. Association between child behavior problems and frequent physician visits. Arch Pediatr Adolesc Med. 1996; 150:146-153

34. Vogel JM, Vernber EM. Task force report: part I: children's psychological response to disasters. J Clin Child Psychol. 1993;22:464-484

35. Costello EJ, Costello AJ, Edelbrock C, et al. Psychiatric disorders in pediatric primary care, prevalence and risk factors. Arch Gen Psychiatry. 1988;45:1107-1116

36. Laraque D, Boscarino JA, Battista A, et al. Reactions and needs of tristatearea pediatricians after the events of September 11th: implications for children's mental health services. Pediatrics. 2004;113:1357-1366

37. Hoven CW. Testimony to United States Senate Field Hearing (Chair, Hillary Rodham Clinton) Senate Health, Education, Labor and Pensions Committee Regarding the Unmet Health Needs of New York City Public School Children as a Result of the September 11th Attacks on the World Trade Center. New York, NY: US Government Printing Office; 2002

38. Foy JM, Earls MF, Horowitz DA. Working to improve mental health services: the North Carolina advocacy effort. Pediatrics. 2002;110: 1232-1237

\section{YOUNG DOCTORS AND WISH LISTS: NO WEEKEND CALLS, NO BEEPERS}

"Dermatology has become one of the most competitive fields for new doctors, with a $40 \%$ increase in students pursuing the profession over the last 5 years, compared with a $40 \%$ drop in those interested in family practice. ... Today's medical residents, half of them women, are choosing specialties with what experts call a 'controllable lifestyle.' Dermatologists typically do not work nights or weekends, have decent control over their time, and are often paid out of pocket, rather than dealing with the inconveniences of insurance.... Other specialties also enjoying a surge in popularity are radiology, anesthesiology, and even emergencyroom medicine, which despite their differences all allow doctors to put work behind them when their shifts end, and make medicine less all-encompassing, more like a 9-to-5 job. What young doctors say they want is that 'when they finish their shift, they don't carry a beeper. They're done.' . . Lifestyle considerations accounted for $55 \%$ of a doctor's choice of specialty in 2002, according to a paper in the Journal of the American Medical Association in September by Dr Rutecki and two co-authors." 